\title{
A intencionalidade da consciência no processo educativo segundo Paulo Freire
}

\author{
Paulo César de Oliveira \\ Universidade Federal de São João Del Rei, São João Del Rei-MG, Brasil \\ Patricia de Carvalho \\ Universidade Vale do Rio Verde, Três Corações-MG, Brasil
}

\begin{abstract}
Resumo: Esse estudo trata a questão da intencionalidade da consciência no processo educativo. O objetivo é mostrar que a conscientização, finalidade última da educação, somente é alcançada mediante a consciência de que o homem está no mundo e com o mundo. A metodologia utilizada consistiu na análise de algumas obras de Paulo Freire que nos permitiram perceber que é, justamente, na praxis, que o homem toma consciência. A esse processo dá-se o nome de "conscientização". Percebeu-se, nesse estudo, que existe uma relação de profunda dependência entre o processo de conscientização, o processo educacional e o processo concreto de libertação do homem.
\end{abstract}

Palavras-chave: Intencionalidade. Consciência. Educação.

\section{Conscious intentionality in the educational process according to Paulo Freire}

\begin{abstract}
This study deals with the question of conscious intentionality in the educational process. The objective is to show that awareness, the final purpose of education, is only reached when man becomes conscious that he is in the world and with the world. The methodology used consisted of analysis of some Paulo Freire writings, which allowed us to perceive that it is in the praxis, that man really takes conscience. This process was called "awareness". It was perceived in this study, that a deep dependence exists between the awareness and educational processes and the concrete process of man liberation .
\end{abstract}

Keywords: Intentionality. Conscience. Education.

\section{La intencionalidad de la consciencia en el proceso de educación según Paulo Freire}

Resumen: Este estudio ocupa de la cuestión de la intencionalidad de la consciencia en el proceso educativo. El objetivo es demostrar que concienciar, finalidad última de la educación, es alcanzada solamente por medio de la consciencia de que el hombre está en el mundo y con el mundo. La metodología usada consistió en el análisis de algunos libros de Paulo Freire que permitió percibir que es justamente, en la praxis, que el hombre adquirí consciencia. A este proceso se da el nombre de "concienciar". Fue percibido, en este estudio, que existe una relación de profunda dependencia entre el proceso de "concienciar", el proceso educativo y el proceso concreto de libetación del hombre.

Palabras clave: Intencionalidad. Consciencia. Educación. 


\section{Introdução}

Paulo Freire iniciou seus trabalhos por volta de 1950 quando, na Universidade de Recife, criou o Movimento de Cultura Popular. Dentro desse movimento, formou um Círculo de Cultura; foi, justamente, a partir de debates com esse grupo inicial que ele chegou à conclusão de que deveria realizar um trabalho no campo da alfabetização de adultos (Vanucchi, 1983). O universo a partir do qual Paulo Freire analisa o processo educacional é o da cultura. Por isso, as obras freireanas escolhidas para fundamentar as reflexões desse artigo enfatizam o vínculo intrínseco entre cultura-conscientizaçãoliberdade.

A idéia central, que perpassa toda a obra de Paulo Freire, é a necessidade de conscientizar, tanto educadores quanto educandos, que "ninguém educa ninguém, os homens aprendem comunitariamente" (Freire, 1970, p. 68). Isto é, à medida que os saberes são trocados, se constrói , conjuntamente, um novo saber; é justamente esse processo que favorece a autonomia do educando. Ele se posiciona, se limita, no campo da pedagogia existencialista. Isto é, concebe o homem como um ser de relações que está no mundo e com o mundo (Oliveira, 2002).

O horizonte da reflexão elaborada por Paulo Freire vislumbra uma prática pedagógica que responda à necessidade de libertação do homem oprimido e à democratização da cultura. Empenha-se na elaboração de um método alfabetizador em que a ação conscientizadora ocupa uma posição relevante e determinante. A importância assumida pela ação conscientizadora na sua obra educativa, sobretudo no seu método, impõe uma reflexão sobre a natureza da consciência, em si mesma, e da conscientização como processo.

O ponto de partida para a sua reflexão sobre a consciência e a conscientização é a constatação do jogo dialético das relações homem-mundo. É nesta ação dialética que ocorre a tomada de consciência, por parte do homem, de sua ligação umbilical com o mundo. É na ação, na práxis, no trabalho, que o homem toma consciência de si, do mundo e dos outros. O colocar em ato a sua possibilidade de transformar o mundo, que também implica ser transformado por ele, é não só seu direito, mas seu dever, uma vez que é através dessa práxis que ele realiza a sua dimensão dialogal e histórica. A tomada de consciência, específica do homem, é conseqüência de sua confrontação com o mundo como algo objetivo, resultado da unidade dialética da subjetividade humana e da objetividade do mundo.

A unidade dialética, subjetividade humana e objetividade do mundo, se transforma em pressuposto para uma correta compreensão do conhecimento e da ação. A incompreensão desta unidade dialética pode levar a dois riscos: ao solipsismo e ao objetivismo. $\mathrm{O}$ erro do solipsismo, postura própria do homem idealista que afirma a exclusividade das idéias no governo do mundo, está no fato de considerar somente o eu existente, sem pensar a realidade externa. Parte da negação da realidade concreta para afirmar a soberania da consciência na criação do próprio mundo. Por outro lado o objetivismo, caracterizado pelo acriticismo, mecanicismo e materialismo, afirma que a realidade transforma-se a si mesma e o homem é apenas passivo nesta transformação. A posição objetivista nega a presença consciente e transformadora do homem, subjugandoo ao mecanicismo, negando-lhe o direito e o dever de operar transformações históricas através de sua decisão.

\section{A intencionalidade da consciência: o homem como corpo consciente}

Paulo Freire constata que, na relação homemmundo, ocorre uma simultaneidade entre a consciência e o mundo: a consciência não precede o mundo e o mundo não precede a consciência. $\mathrm{O}$ mundo é exterior à consciência, mas por essência é relativo a ela. A consciência do mundo implica o mundo da consciência:

Na verdade, não há eu que se constitua sem um não eu. Por sua vez, o não-eu constituinte do eu se constitui na constituição do eu constituído. Desta forma, o mundo constituinte da consciência se torna um mundo da consciência, um percebido objetivo seu, ao qual se intenciona (Freire, 1970, p. 71). 
Afirmando que "o homem é um corpo consciente" (Freire, 1970, p. 74), Paulo Freire coloca a chave para reflexão sobre a intencionalidade da consciência e a ação conscientizadora. Ao expor o seu pensamento sobre a intencionalidade da consciência mostra conhecer a história do problema (Freire, 1969). Não se pode conceber a consciência espacialmente, como um receptáculo vazio presente no homem que deve ser preenchido. A consciência intencional provoca uma aproximação reflexiva à realidade. Não é a realidade que entra na consciência, mas a consciência reflexiva que tende à realidade, criando a possibilidade da práxis com a ação e a reflexão. É sempre uma consciência historicamente condicionada, sem ser uma mera reprodução da realidade.

A consciência humana se define pela sua intencionalidade; é sempre consciência de alguma coisa. É sempre ativa, tem sempre um objeto diante de si, funda o ato do conhecimento, que não deve reduzir-se a uma doxa da realidade, mas deve aprofundar-se para chegar ao logos, à razão do objeto a ser conhecido, o que só é possível quando os homens se unem para responder aos desafios que o mundo lhes propõe.

A consciência não é somente intencionada em direção ao mundo. Ela possui a propriedade de voltarse sobre si mesma e ser consciente de sua consciência. A sua ação ultrapassa o nível do simples reflexo da realidade, da resposta a estímulos externos, para ser reflexiva, alargando-se na reflexão crítica sobre os seus próprios atos e na capacidade de superação de suas contradições. O homem tem a propriedade de transcender a sua atividade: dá sentido ao mundo, elabora objetivos, propõe finalidades.

A consciência permite ao homem não só separar-se do mundo, objetivá-lo, mas também separar-se de sua própria atividade, de ultrapassar as situações-limite.

\section{O homem condicionado pela realidade}

O homem é um ser em situação. Pensar a sua situacionalidade é fundamental para a sua compreensão como um ser de práxis. Em relação ao mundo, o homem pode encontrar-se em três estágios diversos: imersão, emersão e inserção. $O$ primeiro momento é caracterizado pelo fato de que o homem encontra-se totalmente envolvido pela realidade; não consegue pensá-la. $\mathrm{O}$ momento de emersão assinala a capacidade humana de distanciar-se da realidade, de admirá-la objetivando-a. A inserção implica o retorno do homem à realidade para transformá-la através de sua práxis.

O pensar a situacionalidade do homem permite a Paulo Freire falar de diversos níveis de consciência. Não é uma discussão teórica ou psicológica, mas histórica, pois visa colher o homem tal como se apresenta em um momento específico da sua história (Freire, 1967).

O espaço geográfico de seus estudos é o Brasil que viveu, nas décadas de 50,60 e 70 do século XX, um especial período de transição. Tal situação encontrava as suas raízes no passado da história brasileira, mas que no momento apresentava promissoras perspectivas de mudança, com possibilidades reais de contribuição para autonomia e libertação do homem e da nação. Simultaneamente, havia o risco de agravamento da situação de dependência colonial, que reduzia o homem brasileiro a objeto a ser desfrutado por uma pequena elite, que se sentia a única responsável pela construção da história e pronúncia do mundo.

Para o Brasil, estas três décadas constituem, historicamente, um período marcado por um espírito nacional desenvolvimentista, que desejava implantar no país as estruturas industriais modernas existentes no "primeiro mundo", sobretudo Estudos Unidos da América e Europa. Da parte do Brasil, era uma resposta às novas exigências do mercado internacional, que constituía uma nova modalidade de operar a colonização. Internamente, o fenômeno provoca instabilidade econômica, social e política. A industrialização agravava o problema das migrações internas, que trazia consigo um processo de descaracterização do homem brasileiro que, ao vir para as cidades, perdia as suas raízes culturais e não encontrava uma infra-estrutura adequada que propiciasse a sua integração no novo mundo urbano.

É este específico momento de trânsito da sociedade brasileira, com suas possibilidades, que 
permite a Paulo Freire falar de diversos níveis de consciência. Estes níveis podem ser percebidos quando o homem passa do estado de imersão para um novo estado de emersão, isto é, a passagem de uma intransitividade da consciência para uma transitividade ingênua (Paiva, 1980).

\section{Consciência intransitiva}

A consciência intransitiva se caracteriza fundamentalmente pelo fato de que o homem tem o seu interesse voltado para as formas vegetativas de vida; a sua esfera de apreensão da realidade é limitada à dimensão biológica. Nesta fase, o homem não age em nível histórico, não se compromete existencialmente através da decisão, é impermeável aos compromissos que ultrapassam a esfera de vida vegetativa. $\mathrm{O}$ homem assume uma postura mágica diante do mundo e dos fatos; não consegue discernir a verdadeira causalidade dos eventos. É importante sublinhar que a situação de intransitividade não destrói no homem a sua abertura fundamental a ser mais; isto possibilita a passagem para o estado de transitividade.

Esta constatação justificará todo o investimento do processo educativo - conscientizador que se fundamenta na capacidade estrutural do homem de educar-se, capacidade que não foi destruída, mas apenas obscurecida. Nesta perspectiva, afirma Paulo Freire que:

(...) o conceito de 'intransitividade' não corresponde a um fechamento do homem dentro dele mesmo, esmagado, se assim o fosse, por um tempo e um espaço todo poderosos. O homem, qualquer que seja o seu estado, é um ser aberto. O que pretendemos significar com a consciência 'intransitiva' é a limitação de sua esfera de apreensão. É a sua impermeabilidade a desafios situados fora da órbita vegetativa. Neste sentido e só neste sentido, é que a intransitividade representa um quase descompromisso do homem com a existência (Freire, 1970, p. 60).

\section{Consciência transitiva}

$\mathrm{O}$ homem, provocado a responder às questões que lhe são propostas, se impermeabiliza, instaura e aprofunda o processo de diálogo com o seu mundo e com os homens. As suas preocupações não são restritas à esfera vital, mas é capaz de comprometerse. Esta fase se concretiza em momentos distintos: a consciência transitiva ingênua e a consciência transitiva fanática.

A consciência transitiva ingênua é aquela que amplia o poder de captação e de resposta às sugestões que partem do seu contexto. Seus interesses e preocupações se alongam a esferas bem mais amplas que a simples esfera vital. É a consciência típica do homem massa que não consegue estabelecer uma progressão intensiva no diálogo com o mundo e com os homens.

A expressão "homem massa" quer significar a condição do homem que tem o seu agir determinado por forças sociais. Neste estado, o homem não consegue agir conscientemente, não intervém substancialmente na vida social, pois não estabelece uma ação reflexiva e crítica com o mundo e com os outros. É o homem que não cria a sua identidade, mas vive a que é atribuída pelas forças determinantes da sociedade.

A sua relação dialogal é caracterizada pela sua "incapacidade" de interpretar exaustivamente os problemas, de conhecer a causalidade dos fatos, de avançar a sua investigação, acomodando-se às "explicações fabulosas" da realidade e é caracterizada pela fragilidade da argumentação. A sua ação é preponderantemente emocional, não estabelece o diálogo, mas a polêmica, permanecendo marcada pela nota mágica, própria da intransitividade. Tende a voltar nostalgicamente ao passado, como se aquele tempo fosse o melhor. Despreza o homem simples e possui forte tendência gregária. Não é uma consciência investigadora, mas é uma consciência que se comtenta com as experiências vividas; parte do princípio de que a realidade é estática (Freire, 1981).

A massificação é sempre uma possibilidade para a consciência que, "transitivando-se", não consegue a promoção da ingenuidade à criticidade. Ela se caracteriza por um descompromisso com a existência num nível mais profundo que o da intransitividade. $\mathrm{O}$ homem age à base da emocionalidade, se acomoda à estrutura existente, é 
incapaz de realizar opções. Esta situação pode ser denominada de transitividade fanática, que se caracteriza por seu aspecto místico, preponderantemente irracional. A possibilidade de diálogo é praticamente suprimida. $\mathrm{O}$ homem se crê livre, mas é conduzido; na verdade, torna-se um objeto e o seu poder criador é afetado.

Ocorre constatar que o estado do homem massificado é mais grave e profundo que o estado do homem de consciência intransitiva. A massificação, isto é, a consciência fanática, é uma distorção da consciência transitiva que deveria evoluir para ser transitiva crítica. Esta constatação dos diversos níveis de consciência mostra que eles não são produto de um autodesenvolvimento da racionalidade humana, com momentos de uma sucessão natural, que acontece independentemente de um fator externo, mas são resultantes de uma confluência de fatores históricos. Isto leva a perguntar sobre a relação existente entre a consciência e a estrutura social. Revela que, se os níveis de consciência são historicamente formados, podem ser historicamente alterados. É neste processo de amadurecimento da consciência que a educação exerce um papel decisivo: deve estar conjugada com o processo de mudança social (Freire, 1981).

A transitividade crítica se faz conhecida pela sua capacidade de perceber a causalidade dos fatos. Às vezes é chamada simplesmente de consciência crítica e se caracteriza pela profundidade na interpretação dos problemas. A consciência crítica é o conhecimento ou a percepção que consegue revelar algumas razões que explicam a maneira como os homens estão sendo no mundo; ela conduz o homem à sua vocação ontológica e histórica de humanizarse; fundamenta-se na criatividade e estimula tanto a reflexão quanto a ação do homem sobre a realidade, promovendo a transformação criadora.

A consciência transitiva crítica é fruto de uma educação dialogal e ativa que ofereça ao homem a possibilidade de tornar-se responsável no seu agir pessoal, social e político.

A criticidade para nós implica na apropriação crescente de sua posição no contexto. Implica na sua inserção, na sua integração, na representação objetiva da realidade. Daí a conscientização ser o desenvolvimento da tomada de consciência. Não será, por isso mesmo, algo apenas resultante das modificações econômicas, por grandes e importantes que sejam. A criticidade, como entendemos, há de resultar de um trabalho pedagógico critico, apoiando em condições históricas propícias" (Freire, 1981, p. 61).

É interessante perceber dois elementos nestas palavras de Paulo Freire: primeiro, a ligação de dependência que estabelece entre conscientização, criticidade e educação; e segundo, a afirmação de que a conscientização é o desenvolvimento da tomada de consciência. Esta posição será reestruturada nas suas obras posteriores, reconhecendo que não existe conscientização sem práxis transformadora da realidade. Esta fase se caracteriza pelo estabelecimento maduro do diálogo, pela abertura ao novo, construído sobre o que é válido do velho. Ela existe nos regimes democráticos que possuem formas de vida interrogadoras e dialogais.

Ressalto o fato de que, para Paulo Freire, a passagem da consciência transitiva ingênua para a consciência transitiva crítica ocorre através de um trabalho educativo crítico. Nesta perspectiva, ele afirma:

(...) o que nos parecia importante afirmar é que o outro passo, o decisivo, da consciência dominantemente transitivo-ingênua para a dominantemente transitivo-crítica, não daria automaticamente, mas somente por efeito de um trabalho educativo crítico com esta destinação. Trabalho educativo advertido do perigo da massificação, em íntima relação com a industrialização, que nos era e é um imperativo existencial (Freire, 1967, p. 62).

\section{O significado de "conscientização"}

Paulo Freire esclarece que não é ele o autor do vocábulo conscientização (Freire, 1980, p. 25), naturalmente associado ao seu "método de alfabetização". A expressão é resultado de uma reflexão conjunta dos professores do Instituto Superior de Estudos do Brasil (ISEB), por volta do ano de 1964 (Vannucchi, 1983). Foi no ISEB que Paulo Freire 
ouviu pela primeira vez a palavra conscientização; ficou impressionado com a profundidade do seu significado e percebeu que a educação, como ato de conhecimento e como prática da liberdade é conscientização (Oliveira, 2002).

Ao sentir a profundidade do significado do termo, Paulo Freire o assume como instrumento para expressar as suas posições pedagógicas, seguro de que uma educação como prática da liberdade, deve ser eminentemente conscientizadora. A difusão internacional da expressão, diz Paulo Freire, se deve ao trabalho de Dom Hélder Câmara que a tornou conhecida, sobretudo, nos Estados Unidos da América e na Europa.

A palavra conscientização passou a fazer parte do universo vocabular de Paulo Freire. Ele lhe conferiu um conteúdo político-pedagógico tão particular que pode ser considerado, como muitos pensam, o "pai" dessa palavra.

O termo conscientização foi difundido pelo mundo; no entanto, o seu significado foi deturpado de tal forma que Paulo Freire chegou até mesmo a deixar de usá-lo. No seu sentido original, conscientização implicava ação, isto é, uma relação particular entre o pensar e o atuar. Uma pessoa que se conscientiza é aquela que é capaz de descobrir (desvelar) a razão de ser das coisas. Essa descoberta é acompanhada de uma ação transformadora, isto é, de uma organização política que possibilite a ação. Tanto o educador quanto o povo se conscientizam mediante um movimento dialético entre a reflexão crítica sobre a ação interior e a subsequente ação no processo da luta libertadora. A conscientização é, para Paulo Freire,

o desenvolvimento crítico da tomada de consciência. A conscientização comporta, pois, um ir além da (apreensão) fase espontânea até chegar a uma fase crítica na qual a realidade se torna um objeto cognoscível e se assume uma posição epistemológica procurando conhecer (Freire, 1980, p. 290).

A expressão conscientização, derivada do verbo conscientizar, não pode ser substantivizada, pois quer expressar a realidade da consciência em ato: ato de conscientizar, como um processo dinâmico e permanente em que toma ciência de si, de sua ação, do mundo e dos outros como realidades dialeticamente em determinação. Conscientização é um processo pedagógico que busca dar ao ser humano uma oportunidade de descobrir-se através da reflexão sobre a sua existência.

$\mathrm{O}$ vocábulo consciência dá origem ao verbo conscientizar, que indica o dinamismo, a ação de "tomar consciência de". Justamente por isso, para compreender o processo e a prática da conscientização é preciso conectá-la com a compreensão que se tem da consciência na sua relação com o mundo, que ao longo da história deu origem a dois posicionamentos diferentes: ao idealismo que, ao separar consciência e realidade, submete a realidade à consciência, acreditando que a realidade se transforma à medida que se transforma a consciência; ao mecanicismo que toma a consciência apenas como reflexo da realidade. São duas posições extremistas que impossibilitam o processo de conscientização, pois não percebem a relação dialética existente entre objetividade e subjetividade, realidade e consciência, prática e teoria.

\section{Da consciência do mundo à conscientização}

Paulo Freire, ao falar da intencionalidade da consciência, deixou claro o fato de que a consciência é sempre consciência de alguma coisa. Não existe consciência humana sem consciência da realidade concreta, palco onde se desenvolve o drama da construção do homem histórico. O conhecimento da realidade, da parte do homem como autor e ator principal do drama histórico, é determinante para o desenvolvimento da consciência que possui de si; influencia o conhecimento que constrói a partir da realidade que o circunda e que é obra de suas mãos. O tipo de conhecimento que possui da realidade determina a sua postura transformadora:

(...) posto diante do mundo, o homem estabelece uma relação sujeito-objeto da qual nasce o conhecimento que ele expressa por uma linguagem. Esta relação é feita também pelo 
analfabeto, o homem comum. A diferença entre a relação que ele trava neste campo e a nossa é que sua captação do dado objetivo se faz via preponderantemente sensível. A nossa, por via preponderantemente reflexiva. Deste modo surge da primeira captação uma compreensão preponderantemente 'mágica' da realidade. Da segunda, uma compreensão preponderantemente crítica. Como toda compreensão de algo corresponde, cedo ou tarde, a uma ação, a uma compreensão preponderantemente mágica corresponderá também uma ação mágica (Freire, 1981, p. 67).

No processo de conscientização, a realidade não pode ser vista como uma realidade já determinada, pronta, mas como algo que está sendo e que implica a interação realizada pelo homem, através de sua práxis, entre a permanência e o movimento, o novo e velho. A práxis humana, por ser sempre uma entre muitas possibilidades, não pode ser absolutizada, mas deve ser desvelada pela prática teórica, pela reflexão. Não é possível falar em conscientização sem este desvelamento da realidade objetiva, sem essa tomada de consciência da realidade por parte do homem.

A consciência e a conscientização são realidades coligadas, mas não podem ser identificadas. A conscientização pressupõe a capacidade humana de tomar consciência dos fatos. Esta capacidade de tomar consciência de é conatural ao homem, funda o posterior desenvolvimento do processo de conscientização. É o pressuposto que permite ao homem captar o fato de que se encontra em contínua relação dialética com o mundo e com os outros homens, co-participantes do seu drama histórico.

Em contraposição à capacidade natural do homem de tomar consciência, Paulo Freire constata que a opressão deforma a consciência, mas não a suprime. À consciência oprimida não é possível uma visão estrutural da realidade; está impossibilitada de perceber a causalidade dos fatos e seu nexo estrutural; não vê que os fatos históricos são produtos humanos e não materialização da vontade divina, das forças do destino ou de outras forças superiores ao homem.
Ao homem é possível afastar-se do mundo para admirá-lo, objetivá-lo, tornando-o objeto de sua práxis. A percepção crítica da realidade não é imediata, mas sucede, como possibilidade, a uma primeira relação espontânea caracterizada pela ingenuidade. Neste primeiro nível, o conhecimento resultante é restrito à doxa grega, não atingindo o logos da realidade.

Em um primeiro momento, a conscientização é a evolução crítica da primeira tomada de consciência; substitui a primeira apreensão espontânea e ingênua da realidade por uma posição epistemológica crítica que corresponde ao desejo humano de compreender e apoderar-se da realidade que o circunda. À dinamicidade progressiva da conscientização corresponde um progressivo desvelamento da realidade que culmina na práxis, ação e reflexão, típica forma de ser do homem no mundo que manifesta a sua vocação ontológica de ser mais.

A conscientização supõe uma consciência progressiva que conduz o homem a um compromisso histórico não intelectualístico, mas de inserção crítica e engajamento. Engajamento que é participação na atividade comum de fazer e re-fazer o mundo, criando a existência a partir do que a natureza oferece. Ao oprimido não basta saber-se oprimido; mas a conscientização deve inseri-lo em um processo de transformação da realidade.

\section{O que não é conscientização}

Para caracterizar o que não é conscientização, reportamo-nos à conferência intitulada "Desmitificação da conscientização", pronunciada por Paulo Freire em Cuernavaca, México, no Centro Intercultural de Documentação - CIDOC (Torres, 1977). O passar do tempo revelou que a conscientização, como expressão e método, não é unívoca, mas suscita reações diversificadas segundo os interesses em jogo, sendo sempre passível de manipulação ideológica.

Um grupo de pessoas procura na conscientização um poder mágico que resolva os conflitos 
e traumas de natureza emocional, resultantes da crise de valores da sociedade contemporânea que fraturou a relação entre uma geração mais jovem e outra mais velha. Este grupo frusta-se ao constatar que, mesmo iniciando o processo de conscientização, os problemas de ordem emocional não são resolvidos. A sua tendência é a de abandonar o processo de conscientização para fechar-se em um círculo de destruição neurótica.

Um outro grupo vê na conscientização o instrumento milagroso para a concretização de uma ação revolucionária capaz de transformar a realidade. Uma vez iniciado o processo de conscientização constata-se que esta expectativa não encontra a resposta esperada. Ao constatar que é difícil para a consciência dominada haver uma visão clara da realidade, a tendência do grupo é cair na ilusão idealista que conduz ao objetivismo: conclui que a consciência é cópia, reflexo da realidade e, portanto, a solução está na transformação da realidade, o que provocaria a imediata transformação da consciência. Trata-se de uma visão mecanicista do processo de transformação (Freire, 1969).

Um outro grupo de pessoas, ao participar da problemática social, deseja contribuir na solução dessa questão com a proposição de soluções conciliatórias, certo de que é possível transformar o homem sem transformar o mundo. A conscientização seria uma alternativa à luta de classes. Esse grupo, sem saber, é manipulado ideologicamente pelas estruturas dominadoras. A sua ação é uma mitificação do amor, isto é, uma distorção do verdadeiro amor que deve levar à integração e não a um processo de acomodação. É uma posição idealista; acredita que a consciência é criadora da realidade e a sua ação tem origem na convicção de que a libertação do homem está dentro de sua consciência, independente da estrutura social.

Para um outro grupo, a conscientização é um "processo de satanização", isto é, um processo perturbador da ordem estabelecida. Esse grupo conhece o poder transformador da conscientização e procura combatê-la, eliminá-la, para manter o seu status quo. Usa como instrumento de combate um processo de mitologização, isto é, procura criar na opinião pública a convicção de que a ação conscientizadora corresponde a uma ação satânica, e por se constituir em perigo para todos, deve ser radicalmente rejeitada.

Apenas um pequeno grupo é capaz de assumir a conscientização como processo crítico e dialético, que integra subjetividade e objetividade, consciência e mundo. Esse grupo parte do pressuposto de que não existe homem sem mundo e mundo sem homem; que não há mundo sem que seja mundo de consciência. Conscientizar, para esse grupo, é criar e recriar, é integração de ação e reflexão, é compreender dialeticamente os problemas sociais (Freire, 1970).

\section{Características da conscientização}

$\mathrm{O}$ primeiro caráter distintivo fundamental da conscientização é o pressuposto que a torna possível: a consciência intencional. A conscientização, fenômeno tipicamente humano, é possível desde o momento em que a consciência se torna reflexiva. Como possibilidade ela não é um fenômeno típico do terceiro mundo, mas é comum ao homem enquanto corpo consciente, relacionado dialeticamente com a realidade. $\mathrm{O}$ que altera, ao longo da história, são os seus conteúdos, os seus métodos e os seus objetivos.

Para Paulo Freire o conceito de terceiro mundo não é somente geográfico, mas ideológico e político. O primeiro mundo manifesta, através de suas contradições, o terceiro mundo que trás dentro de si. Através da elite dominante e da distribuição do poder, o terceiro mundo manifesta o primeiro mundo dentro de si. O terceiro mundo é sempre o mundo do silêncio, da opressão e da dependência. A sociedade consumista não precisa ir à América Latina ou à África para sentir o terceiro mundo; basta olhar para as periferias de suas grandes cidades para sentir o drama dos que são colocados à margem da história e do progresso (Freire, 1976). A esse ponto da reflexão, partindo do pressuposto 
de que o homem não é somente "ser no mundo", mas "ser com o mundo", é claro que a conscientização não se opera em uma consciência isolada do mundo, mas implica necessariamente a dialetização consciência - mundo, pois é dentro da história, através da práxis, que se opera o processo de transformação.

O processo de conscientização não deve encerrar-se no processo de desvelamento da realidade, mas deve prosseguir para a transformação da mesma realidade. $\mathrm{O}$ conjunto do processo supõe uma opção ideológica por parte do sujeito, opção que alimentará o dinamismo do processo de transformação e integração do sujeito no mundo, que contribuirá na organização dos homens para a transformação da realidade desumanizante. Esta opção deixa claro ao homem que ele não será em plenitude se o outro não realizar a sua vocação de ser mais.

$\mathrm{O}$ homem não pode suprimir a força criadora e recriadora da consciência. Por isso o dominador procura mitificar a realidade como meio para também mitificar a consciência. Uma vez mitificada a consciência da realidade, ocorre uma interrupção do processo de transformação da mesma realidade. A ação mitificadora é típica dos dominadores; é sempre a ação de impedir que o homem coloque o porquê das coisas; é a proibição do pensar. $\mathrm{O}$ dominador, ao procurar preservar a sua situação presente, perde o horizonte do futuro e por isso não possui nenhuma esperança.

A conscientização é sempre um ato de amor que pode restituir ao dominador e ao dominado a razão de ser homem. Será a expressão de um amor criativo capaz de destruir para construir; que deseja restituir ao dominado, e em última instância também ao dominador, o direito de ser homem, vocação que é comum a todos. A conscientização é um ato de amor; por isso somente os homens capazes de amar conseguirão levar até o fim o processo de conscientização.

A conscientização realiza-se como uma dialetização do ato de denúncia da estrutura desumanizadora e de anúncio de uma estrutura humanizante. Esta postura utópica, de denúncia e anúncio, supõe um conhecimento crítico da realidade, pois não se denuncia ou anuncia algo que não se conhece. Enquanto anúncio, a conscientização é sempre anúncio de um anteprojeto possível, pois o anteprojeto faz-se projeto enquanto é situado na práxis e se realiza no momento histórico.

Para Paulo Freire somente o homem utópico é profético e portador de esperança. É profético porque está envolvido em um processo que deseja restituir ao homem a viabilidade de poder realizar a sua vocação de ser sujeito. É portador de uma esperança viável que deseja restituir a história aos seus construtores.

A conscientização é uma ação permanente que se encarna na práxis e não se cristaliza na burocratização. Ela deve conduzir o homem a apoderar-se permanentemente da realidade provocando uma contínua revolução cultural. Deve dar origem a uma contínua transformação que não se cristaliza em formas estáticas que poderiam tornar-se formas opressoras incapazes de acompanhar o dinamismo intrínseco da própria conscientização e da história. Este contínuo apoderar-se da realidade e da história deve conduzir à desmitologização que manipula as massas para mantê-las alienadas do processo histórico.

A conscientização é desmistificadora, isto é, mostra ao homem a falsidade do mito da incapacidade ontológica dos oprimidos, o que impede de empenhar-se na superação das "situaçõeslimite".

Esse mito é tão forte que faz o homem convencer-se de sua incapacidade, que não é real, mas criada, ilusória, mas que assume um poder sobre-determinador, fruto da ação do devir histórico; saber que o futuro e o passado são determinados pela ação presente, da qual ele é sempre autor, ou melhor, co-autor com os outros homens, com os quais se encontra em diálogo, mediatizados pelo mundo.

A intensidade do compromisso, do engajamento, da integração do homem, dependerá 
sempre da intensidade do exercício de sua capacidade desveladora da realidade. A conscientização torna-se perturbadora para o homem, desinstala-o de seu ajustamento ao mundo. Se ela não conduz à ação, provoca no homem um sentimento de culpa por não fazer o que deveria, pois sabe-se responsável pela transformação ou manutenção da realidade que submete grande parte dos homens à fome, à tristeza e ao desamor. $\mathrm{O}$ sentimento de culpa leva-o a uma "racionalização" da realidade, conduzindo-o a uma falsa generosidade, que se expressa em uma filantropia assistencialista, na procura de outros caminhos para encontrar a paz. Porém, a paz não existe fora do compromisso com os outros homens na luta comum pela libertação. $\mathrm{O}$ homem conquista a sua paz com os outros.

A opressão imprimiu no homem o medo da liberdade. A conscientização restitui ao homem a coragem de exercitar a sua liberdade, ainda que seja uma liberdade sofrida, mas que conduz sempre ao renascimento. Ao mesmo tempo a liberdade pode constituir-se no único limite para a conscientização, pois esta não pode ser imposta, mas deve ser assumida livremente.

A conscientização pode ser vista como uma pedagogia da revolução, pois faz com que a autenticidade das transformações revolucionárias sejam correspondentes à medida de participação consciente de todo o povo. Ela não pode ser vista como um método neutro, reformista, para integrar o indivíduo na sociedade.

A ilusão idealista-subjetivista sustenta a tese de que é possível transformar o coração do homem mantendo as estruturas que o determinam, isto é, que é primeiro possível transformar a consciência para depois retardar a mudança das estruturas sociais. A consciência não cria a realidade e não tem força para mudar o homem sem mudar as estruturas sociais. Nem mesmo a conscientização pode ser usada como instrumento para estabelecer a harmonia entre as classes sociais, como instrumento de conciliação de pólos inconciliáveis; mas deseja ser um método ideologizado, com um conteúdo político, que visa atingir a práxis social, engajar os indivíduos em uma práxis libertadora.

\section{Considerações finais}

$\mathrm{Na}$ estrutura do pensamento de Paulo Freire conscientização e educação são realidades intimamente conexas que não encontram em si mesmas o seu sentido último: estão a serviço do homem. De fato, segundo Paulo Freire, não é possível passar da consciência ingênua para a consciência crítica sem o auxílio de uma obra educativa. É o momento de repropor uma questão, já anteriormente mencionada. Isto é: deve-se apresentar uma proposta educacional que conscientiza ou uma ação conscientizadora que alfabetiza? À medida que o trabalho se desenvolve fica evidente que a conscientização é muito mais abrangente que a educação.

Existe uma relação profunda de dependência entre o processo de conscientização, o processo educacional e o processo concreto de libertação do homem no pensamento de Paulo Freire. Na sua pedagogia, alfabetizar é sinônimo de conscientizar e conscientizar é transformar. A conscientização se realiza através de uma educação como prática de liberdade, que se contrapõe a uma educação domesticadora a serviço da dominação que reproduz os mecanismos ideológicos que perpetuam os privilégios de uma elite que se considera a proprietária exclusiva do direito de realizar a vocação que é comum a todos os homens. Esta educação domesticadora não consegue suprimir, mas apenas obscurecer, a intencionalidade da consciência que torna possível uma reação de não aceitação e que abre espaço para uma educação que responda às expectativas do homem de realizar a sua humanização.

Uma educação conscientizadora é um instrumento necessário para a libertação do homem, mas per se é insuficiente. É uma educação libertadora que viabiliza ao homem os instrumentos para desvelar a realidade e os mitos criados pela super-estrutura. Ao extirpar os mitos e conhecer a 
realidade, o homem cria uma nova consciência. Ao transformar o mundo, se constrói como novo homem, que recria uma nova história. Essa educação conscientizadora provoca uma revolução cultural, um dinamismo que não deixa cristalizar modelos culturais opressores que possam ser introjetados na consciência dos homens. A percepção desta interrelação revela que qualquer prática pedagógica possui implicações políticas. De fato, não é a educação, isoladamente, que plasma a sociedade, mas é a sociedade constituída que, de acordo com os seus valores diretivos determina a educação, colocando-a a seu serviço e a serviço de sua sustentação. Não é possível conferir à educação o papel de exclusivo agente transformador da realidade, pois o poder político estruturado, ao qual serve, não permite uma sua ação contra o poder estabelecido. E nem mesmo se pode pensar em uma mudança global de um sistema educativo sem a transformação da sociedade que o determina.

Educa-se para um tempo. A educação é um processo que acompanha as mudanças da estrutura sócio-econômica e que deve adequar-se à política que sustenta a dialética das transformações sociais. A educação, apesar de seu caráter dialético superestrutural, limitadamente, pode também funcionar como fator decisivo nos processos de mudança social; no entanto, deve ser conjugada com a mudança das estruturas e a dialética conflitiva da sociedade. É neste sentido que a Pedagogia do Oprimido deseja ser a pedagogia dos homens que se encontram em processo de libertação.

Em síntese pode-se afirmar que a conscientização, ao levar o homem à práxis, implica:

a) o desenvolvimento de sua natureza de pessoa e a necessidade de comprometer-se com as conseqüências desta descoberta;

b) a conquista da consciência transitivo-crítica ao longo de uma progressão de descobrimentos relacionais;

c) a passagem e a emersão da existência oprimida para a consciência do oprimido.
O processo conscientizador é uma contribuição para a dinâmica da libertação do homem, em que a educação vai se convertendo em instrumento das classes oprimidas para subverter os privilégios. Educação e conscientização são, portanto, uma contribuição à transição como ações culturais libertadoras e como rupturas das práticas domesticadoras da educação bancária. São dois momentos de um mesmo processo em que a educação politiza e a política educa.

\section{Referências}

Freire, P. (1967). A educação como prática da liberdade. Rio de Janeiro, RJ: Paz e Terra.

Freire, P. (1969). ¿Extensión o comunicación? La conscientización en el médio rural. Santiago: ICIRA.

Freire, P. (1970). Pedagogia do oprimido. Rio de Janeiro, RJ: Paz e Terra.

Freire, P. (1976). Ação cultural para a liberdade e outros escritos. Rio de Janeiro, RJ: Paz e Terra.

Freire, P. (1980). Conscientização: Teoria e prática da libertação. São Paulo, SP: Moraes.

Freire, P. (1981). A educação e mudança. Rio de Janeiro, RJ: Paz e Terra.

Freire, P. (1982). Importância do ato de ler em três artigos que se completam. São Paulo, SP: Cortez.

Oliveira, P. C. (2002). Conscientização e liberdade na filosofia da educação de Paulo Freire. Tese de Doutorado não publicada, Pontificiam Universitatem S. Thomae, Roma.

Paiva, V. P. (1980). Paulo Freire e o nacionalismo desenvolvimentista. Rio de Janeiro, RJ: Civilização Brasileira.

Torres, C. A. (1977). A práxis educativa de Paulo Freire. São Paulo, SP: Loyola.

Vanucchi, A. (1983). Paulo Freire ao vivo. São Paulo, SP: Loyola. 
Paidéia, 2007, 17(37), 219-230

Artigo recebido em 03/05/2007.

Aceito para publicação em 03/08/2007.

Endereço para correspondência:

Paulo César de Oliveira. Rua Tietê, 316, Bairro Nossa Senhora das Graças, CEP: 37056-100. Varginha -MG, Brasil. E-mail: deoliveirapc@ufsj.edu.br

Paulo César de Oliveira é Doutor em Filosofia e Professor Adjunto do Departamento de Filosofia e Métodos da Universidade Federal de São João del Rei-MG.

Patricia de Carvalho é Mestre em Tecnologia Educacional pela Universidade Federal do Rio de Janeiro e Professora na Universidade Vale do Rio Verde de Três Corações-MG e no Centro Universitário do Sul de Minas de Varginha-MG. 